\title{
Ciclo da água urbano: análise da relação da heterogeneidade espacial e os fluxos de água da Bacia Hidrográfica do Lago Paranoá ${ }^{1}$
}

\section{Urban water cycle: analysis of the relationship of the spatial heterogeneity and the water flows of the Paranoá Lake Basin}

\author{
Rodrigues, Luísa B. ${ }^{\text {; }}$ Andrade, Liza M. S. ${ }^{2}$ \\ ' Universidade de Brasília, QE 09 Conjunto A casa 15 Guará I, Brasília, Brasil, \\ luisabrodri@gmail.com \\ 2 Universidade de Brasília, lizamsa@gmail.com
}

\begin{abstract}
RESUMO
A heterogeneidade espacial pode influenciar as funções ecológicas urbanas e os fluxos de água, como retenção de água superficial. No Distrito Federal a intensa ocupação com impermeabilização do solo e o espraiamento urbano causam distorções no fluxo de água, fragilizando todo o sistema hídrico da cidade. Nem todo o solo residencial é estruturalmente - mesmo, dada à variação da densidade de edificações, vegetação e superfícies impermeáveis. O objetivo desta pesquisa de Iniciação Científica é demonstrar a relação da heterogeneidade espacial e os fluxos de água nos aglomerados urbanos do DF, dando continuidade as pesquisas realizadas por Andrade (2014) sobre os padrões de uso da bacia do Lago Paranoá. Foram levantados dados do percentual de áreas impermeáveis, tipologias predominantes, renda média da população e consumo de água. Os dados encontrados demonstram que quanto maior a área de lote, onde predominantemente habita a população de renda alta, menor a densidade urbana, menor o escoamento superficial, maior o consumo e desperdício de água. Dessa forma, apresenta-se a aplicação de padrões de desenho urbano como soluções de baixo impacto para problemas sociais e ambientais adequados à drenagem urbana. Os desenhos esquemáticos das soluções apresentadas dão continuidade a produção do manual "Brasília sensível a água".
\end{abstract}

Palavras-chave: heterogeneidade espacial, bacia hidrográfica, ciclo urbano da água.

\begin{abstract}
Spatial heterogeneity can influence urban ecological functions and water flows, such as water retention. In Federal District intense occupation with impermeabilization of the soil and urban sprawl cause distortions in the flow of water in the basin with increased surface runoff. Urban water cycle becomes unstable, weakening the city's water system. Not all residential lands are structurally the same, given the density variation of buildings, vegetation and the number of

${ }^{1}$ RODRIGUES, Luísa; ANDRADE, Liza; Ciclo da água urbano: análise da relação da heterogeneidade espacial e os fluxos de água da Bacia hidrográfica do Lago Paranoá In: II SIMPÓSIO NACIONAL DE GESTÃO E ENGENHARIA URBANA: SINGEURB, 2019, São Paulo. Anais... Porto Alegre: ANTAC, 2019.
\end{abstract}


impermeable surfaces. The objective of this Scientific Initiation research was to demonstrate the relationship of spatial heterogeneity and water flows in the urban agglomerations of the Federal District, continuing the research carried out by Andrade (2014) on the use patterns of the Lake Paranoá basin. Data was collected such as the percentage of impermeable areas, typologies, average income and water consumption. Results showed that the larger the plot area, where the high-income population predominates, the lower the urban density, the lower the surface runoff and the greater the consumption and waste of water. Therefore, it is presented the application of several urban design standards as low-impact solutions to social and environmental problems suitable for urban drainage. Schematic drawings of the solutions presented for each area continued the production of the manual "Water Sensitive Brasilia".

Keywords: spatial heterogeneity, hydrographic basin, urban water cycle.

\section{INTRODUÇÃO}

Esta pesquisa está inserida no projeto "Brasília Sensível a Água" (ProlC/UnB 2015-2016; 20162017). Esse projeto tem como finalidade demonstrar o estado crítico de situação das águas do Distrito Federal no contexto das mudanças climáticas e do Bioma Cerrado em relação à demanda por infraestrutura ecológica para novas ocupações urbanas e restabelecimento do ciclo da água urbano.

A situação hídrica no Distrito Federal foi condenada no início do planejamento da capital. O desenho da cidade de Brasília, caracterizada pelos grandes eixos rodoviários e extensas áreas desocupadas, corresponde aos ideais de transporte individual com um sistema de drenagem ainda da logística modernista de canalização das águas. O relatório da ANA "Conjuntura dos Recursos Hídricos Brasil 2017" aponta que nos últimos 16 anos, não houve um planejamento e execução de obras estruturantes de saneamento em Brasília (BRASIL, 2017).

Com as mudanças climáticas, tempestades e ventos fortes, evidencia-se a incapacidade do sistema de conter o escoamento superficial que chega em grande velocidade, levando a consequências catastróficas, como as inundações que ocorreram no dia 21 de abril de 2019 no Plano Piloto. Por outro lado, em 2017 em plena estação chuvosa, os reservatórios chegaram a operar com menos de $20 \%$ da capacidade, instalando-se uma situação de emergência hídrica no Distrito Federal com racionamento rotativo de água, redução da pressão como medida para prevenir a total escassez de dois reservatórios que abastecem a região (AESBE, 2019). Em julho de 2017 foi lançado um programa da Adasa (Agência Reguladora de águas, Energia e Saneamento do Distrito Federal) para drenagem e manejo de águas pluviais urbanas com um orçamento preliminar para a obra de mais de 6 bilhões de reais (ADASA, 2016).

Diante de tal cenário, é tangível a necessidade de repensar os sistemas de infraestrutura hídrica, drenagem, captação e abastecimento, com soluções de baixo custo e menos impacto socioambiental, incorporando soluções ecologicamente e economicamente sustentáveis. A execução de infraestruturas verdes e desenhos urbanos estratégicos se mostram indispensáveis para a conversão do atual quadro hídrico do Distrito Federal.

Este trabalho tem como objetivo demonstrar que por meio do diagnóstico da morfologia urbana é possível relacionar a heterogeneidade espacial do Distrito Federal com os fluxos de água da bacia hidrográfica do Lago Paranoá.

\section{MATERIAL E MÉTODOS}

A heterogeneidade espacial do mosaico urbano vem se tornando um aspecto importante para avaliar a funcionalidade ecológica, os fluxos de água e o contexto social. Pesquisadores do "Cary Institute of Ecosystems Study" dos EUA analisam a cidade como ecossistema urbano, que abrange todos os processos que sustentam os recursos naturais e humanos, integrando os componentes biológicos, físicos, sociais e do ambiente construído (ANDRADE, 2014). A heterogeneidade espacial é abordada por Andrade (2014) a partir da perspectiva de Pickett e Cadenasso (2013) que conotam o conceito da ecologia como uma colcha de retalhos, 
ilustrando as diferentes características presentes em manchas urbanas. Tais características de interesse (CADENASSO e PICKETT, 2013 apud ANDRADE, 2014 p. 165), são organizadas segundo a "quantidade de superfícies impermeáveis, coberturas arbóreas, tipos edilícios, consumo de água e classe social", ou seja, o mosaico natural das aglomerações urbanas. A investigação dessas manchas urbanas é essencial na análise do ciclo da água, tendo em vista a complexidade desses padrões espaciais e suas transformações ao longo do tempo.

Assim, os procedimentos metodológicos adotados dão continuidade aos estudos de Andrade (2014) sobre padrões espaciais dos ecossistemas urbanos a partir do cruzamento de dados, possibilitando o entendimento dos padrões espaciais da Bacia do Paranoá. Referências foram retiradas do Plano de Gerenciamento Integrado de Recursos Hídricos do DF, a avaliação das ações antrópicas no processo de escoamento superficial e assoreamento na Bacia do Lago Paranoá de Andrade e Ribas (2012), estudos de Sant'Ana (2010) sobre o consumo e conservação da água em Brasília, juntamente com estudos trazidos por Menezes (2010) e Tucci (2008) sobre escoamento superficial bem como a relação dos dados socioeconômicos com padrões espaciais nos estudos de Holanda (2010). Foram coletados dados das instituições ADASA, Caesb e CODEPLAN para sistematizar a correlação entre padrões de uso e ocupação do solo, tipos edilícios, taxa de permeabilidade, escoamento, consumo de água e a renda dos habitantes.

Com base no Programa "City of Melbourne Water Sensitive Urban Design Guidelines" (WSUD) da Austrália, 2008, no desenho urbano sensível à água e nos 38 padrões espaciais elencados por Andrade (2014), propôs-se por meio de desenhos esquemáticos estratégias para cada tipo de uso do solo da Bacia do Lago Paranoá (Figura 1). Esses padrões são métodos e estruturas elaborados por diversos autores e compilados na pesquisa de Andrade (2014) como importantes estratégias sustentáveis, a serem aplicadas no desenho urbano, para promover a manutenção do ciclo hidrológico no meio urbano. Foram selecionados alguns desses padrões como possíveis soluções de baixo impacto e de alta eficácia a serem adotadas nas regiões administrativas do Distrito Federal como estudo de caso.

Figura 1 -Padrões espaciais selecionados

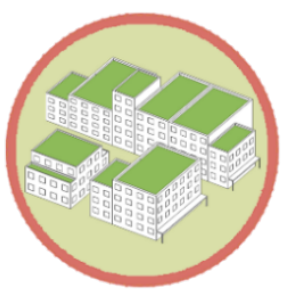

1.Telhado verde

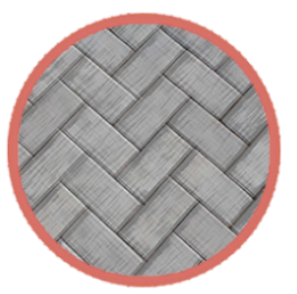

2.Pavimentação porosa

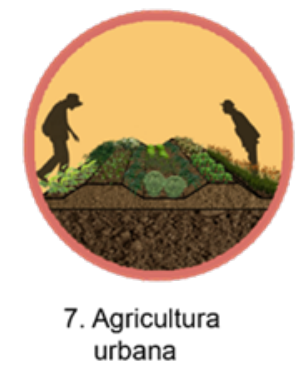

7. Agricultura urbana

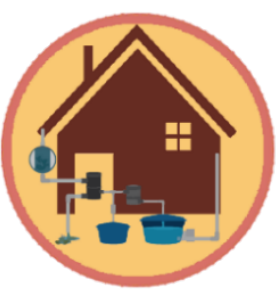

3. Captação e reuso de água

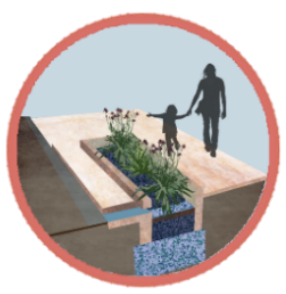

4. Jardim de chuva

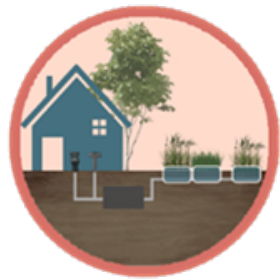

9. Máquinas vivas

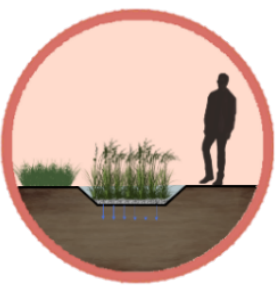

5. Biovaleta

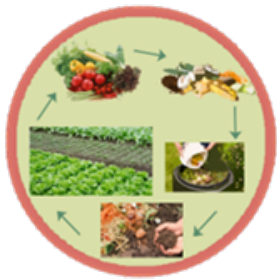

6. Compostagem

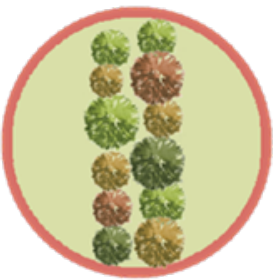

8. Parque linear

Fonte: Rodrigues (2017) 


\section{OS PADRÕES DE USO E OCUPAÇÃO DO SOLO NA BACIA HIDROGRÁFICA DO LAGO PARANOÁ}

De acordo o Plano de Gerenciamento Integrado de Recursos Hídricos (2011) o levantamento de dados sobre uso e cobertura do solo viabiliza a quantificação das áreas ocupadas por cada tipo de uso e a relação destes com as demandas por recursos hídricos nas áreas de estudo.

A bacia do Lago Paranoá, juntamente com as outras bacias que ocupam o DF, são responsáveis pela estrutura e drenagem da região. Subdividida em 5 unidades hidrográficas, a bacia se localiza na área de maior adensamento do DF, segundo Menezes (2010), conforme Fig.2. O pesquisador também afirma que na Bacia do Paranoá predominam os solos com alta taxa de infiltração e alto grau a resistência e tolerância à erosão.

Figura 2 - Bacias Hidrográficas do DF:

1.Bacia do Maranhão; 2. Bacia do Descoberto, 3. Bacia do Lago Paranoá, 4. Bacia do São Bartolomeu, 5. Bacia do Preto, 6. Bacia do Corumbá, 7. Bacia do São Marcos. Unidades hidrográficas da Bacia do Lago Paranoá: 3a. Santa Maria/Torto 3b. Bananal 3c. Lago Paranoá 3d. Riacho Fundo 3e. Ribeirão do Gama

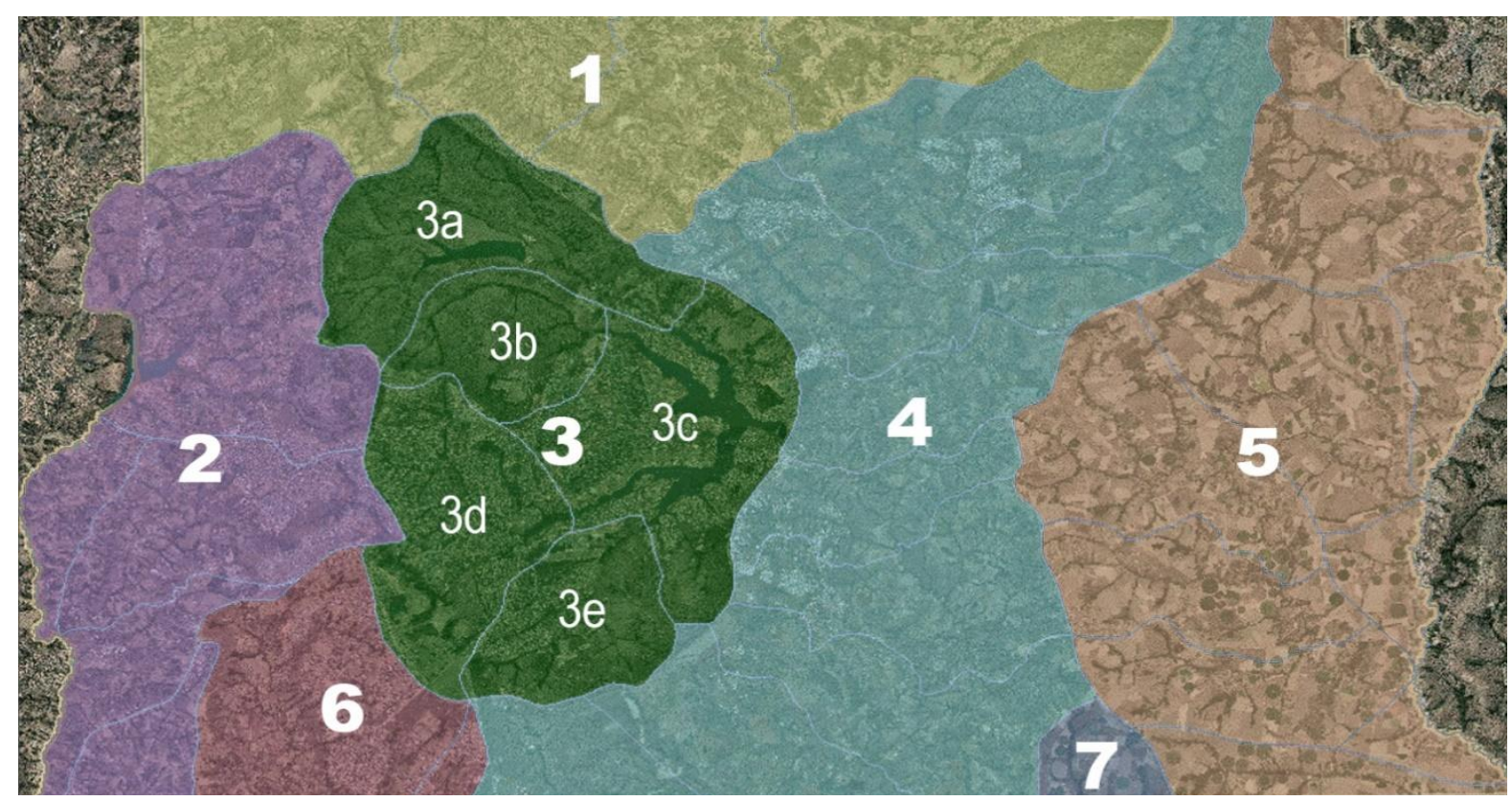

Fonte: Adaptado do Geoportal Segeth DF(2017)

Segundo os dados da Adasa (2017) o período de maior déficit crítico de água é entre o período de julho e setembro, justamente na estação seca, na qual o clima é caracterizado por baixa umidade e pluviosidade, intensa insolação e alta evaporação.

De acordo com Menezes (2010), a expansão urbana do DF altera a cobertura do solo, aumentando o percentual de impermeabilização de toda a região (Fig.3). O pesquisador avaliou ao longo dessas transformações urbanas a elevação das taxas de escoamento superficial em todas as 5 unidades hidrográficas da bacia do Paranoá, comprovando a relação entre taxa de ocupação, características do solo, áreas impermeáveis e escoamento superficial. 
Figura 3 - Confrontação de Mapas: (a) Classificação de uso e ocupação de solo; (b) Grupos hidrológicos de solos da Bacia do Paranoá; (c) Porcentagem de precipitação excedente para evento simulado de uma precipitação de 50mm.

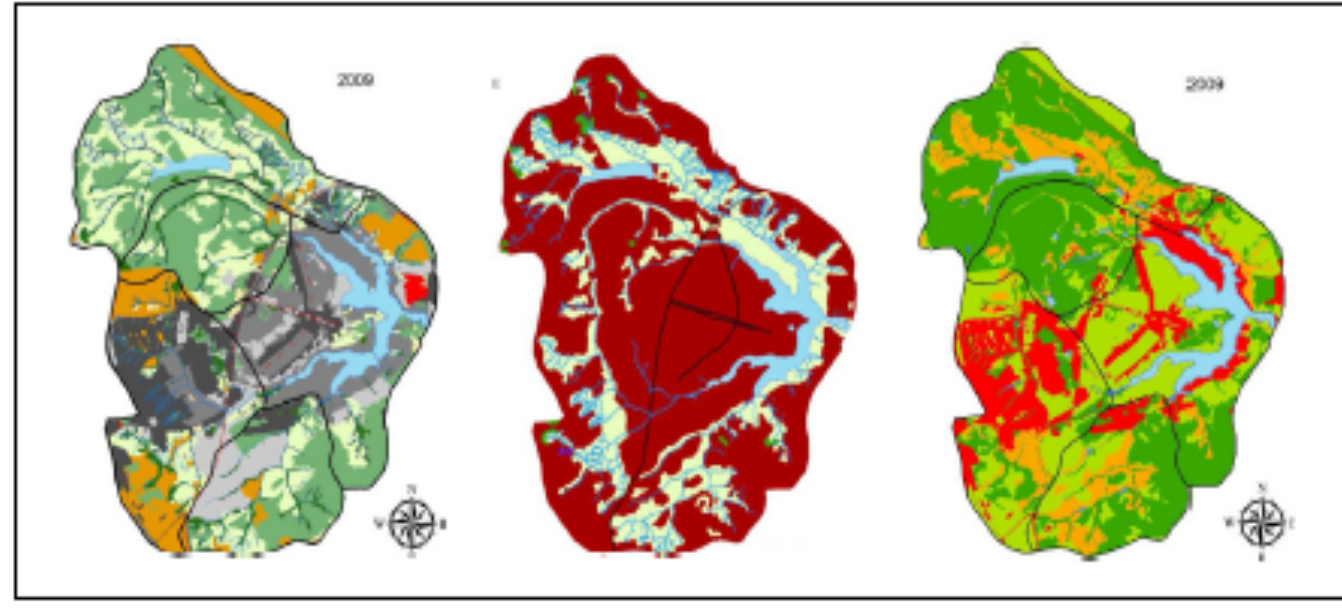

\section{Legenda}

Drenagem

Vias Principais

Corpos dagua

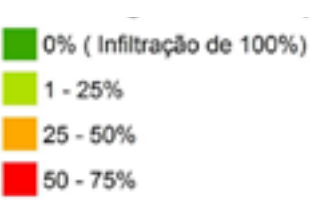

edente

Fonte: Adaptado de Menezes (2010)

\section{ANÁLISE DA HETEROGENEIDADE ESPACIAL DA BACIA DO PARANOÁ POR REGIŌES ADMINISTRATIVAS (RA's)}

As Regiões Administrativas foram escolhidas com base na pesquisa de Menezes (2010) que divide as regiões segundo o percentual de permeabilidade (Fig.4), ao qual a área urbana 1 tem $<40 \%$, a área urbana 2 tem entre 40 e $70 \%$ e a área urbana 3 tem $>70 \%$ de área permeável.

Figura 4 - (RA's): Asa Sul, Cruzeiro, Guará, Lago Norte e Sul, Núcleo Bandeirante, Paranoá, Park Way

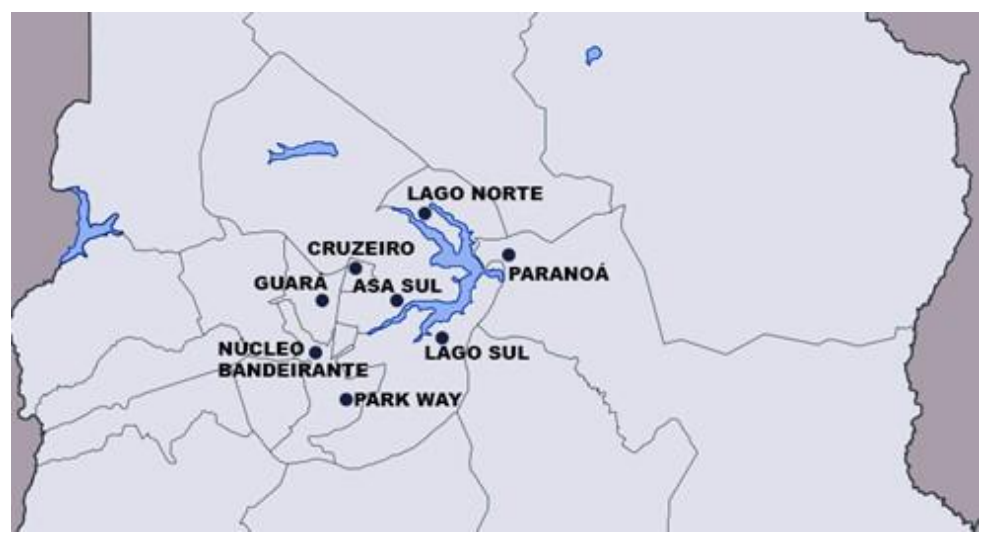

Fonte: Adaptado da Codeplan (2017) 


\section{RESULTADOS}

Tendo em vista a análise de Sant'Ana (2011) da correlação entre renda familiar, tipologia edilícia e consumo de água por pessoa, avaliou-se o consumo de água das regiões administrativas do ano de 2016 (Figura 5).

Figura 5 - Consumo de água/pessoa/dia no DF EM 2017

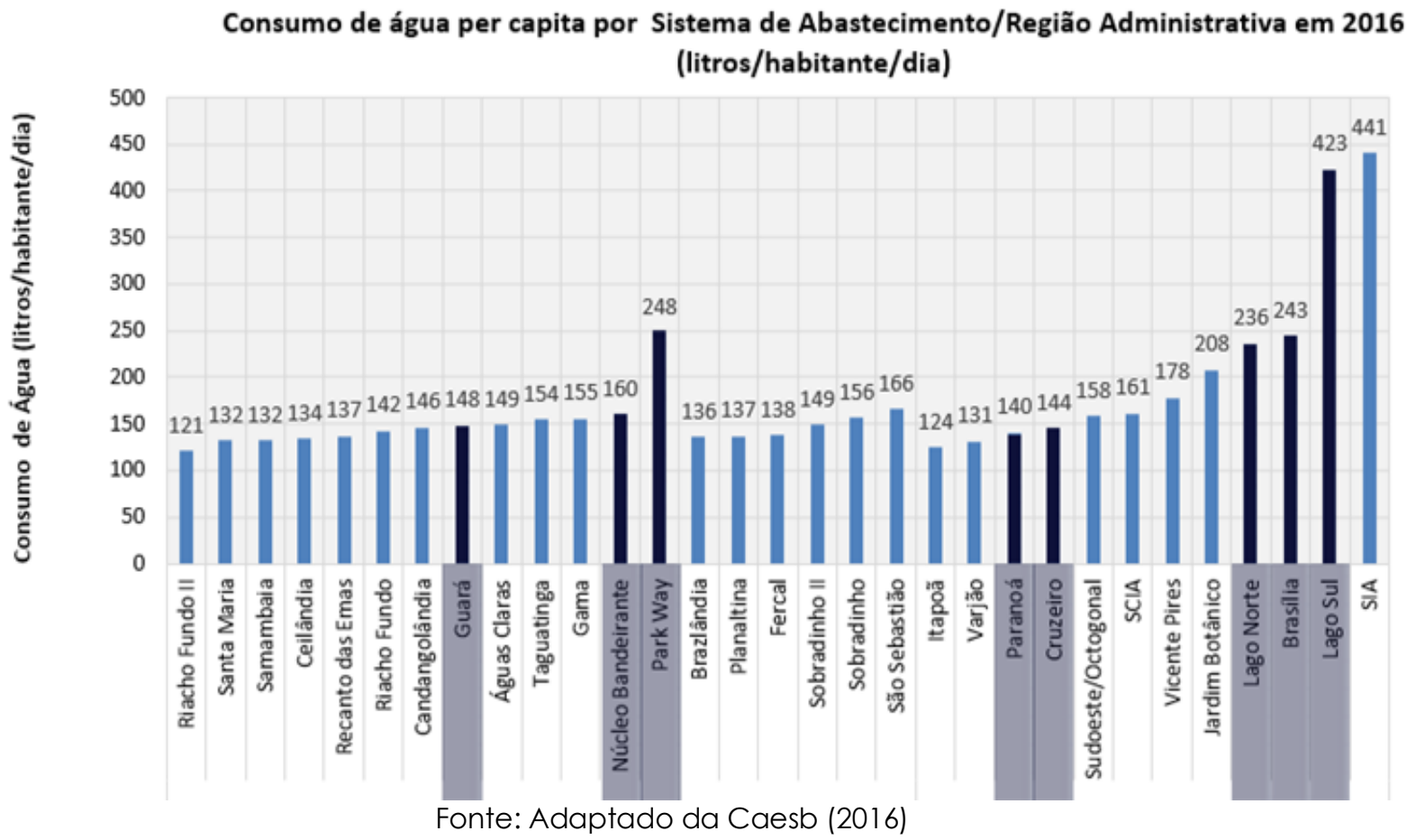

Sant'Ana observou que as regiões administrativas que abrigam a população de maior renda apresentam maior consumo de água, já que nas residências dessas regiões há mais elementos que utilizam água, como piscina, jardins e aparelhos sanitários. Holanda (2007) ressalta que o tamanho do lote e tipologia arquitetônica relaciona-se com a renda.

\subsection{Síntese dos Padrões Espaciais}

A partir do cruzamento de informações sobre padrão de uso do solo (Quadro 1), percentual de área impermeável (Figura 3), tipologia edilícia (Quadro 1), faixa de renda da população (Quadro 1) e consumo de água em 2016 (Figura 5), estabeleceram-se os padrões espaciais (Figura 1). Concluiu-se que para as áreas urbanas 1 e 2 de baixa densidade, renda alta, por conseguinte, elevado consumo de água e por possuírem lotes acima de $12 \mathrm{mil} \mathrm{m}^{2}$, são ideais para a compostagem, captação e reuso da água, máquinas vivas (tratamento de esgoto), telhado verde, biovaletas (valas com vegetação para transporte pluvial) e tanque de evapotranspiração (reuso das águas negras por plantas).

Áreas urbanas 2 com renda média alta, médio consumo de água e tipologia multifamiliar são potenciais para telhado verde, jardim de chuva, reuso de água, agricultura urbana e compostagem. Já para as áreas urbanas 3 com média e baixa renda, consumo baixo de água e mais adensados, foi proposto pavimentação porosa, parques lineares, jardim de chuva, além de telhado verde, reuso de águas e tanque evapotranspiração quando viável economicamente. 
Quadro 1 -Padrões espaciais aplicados

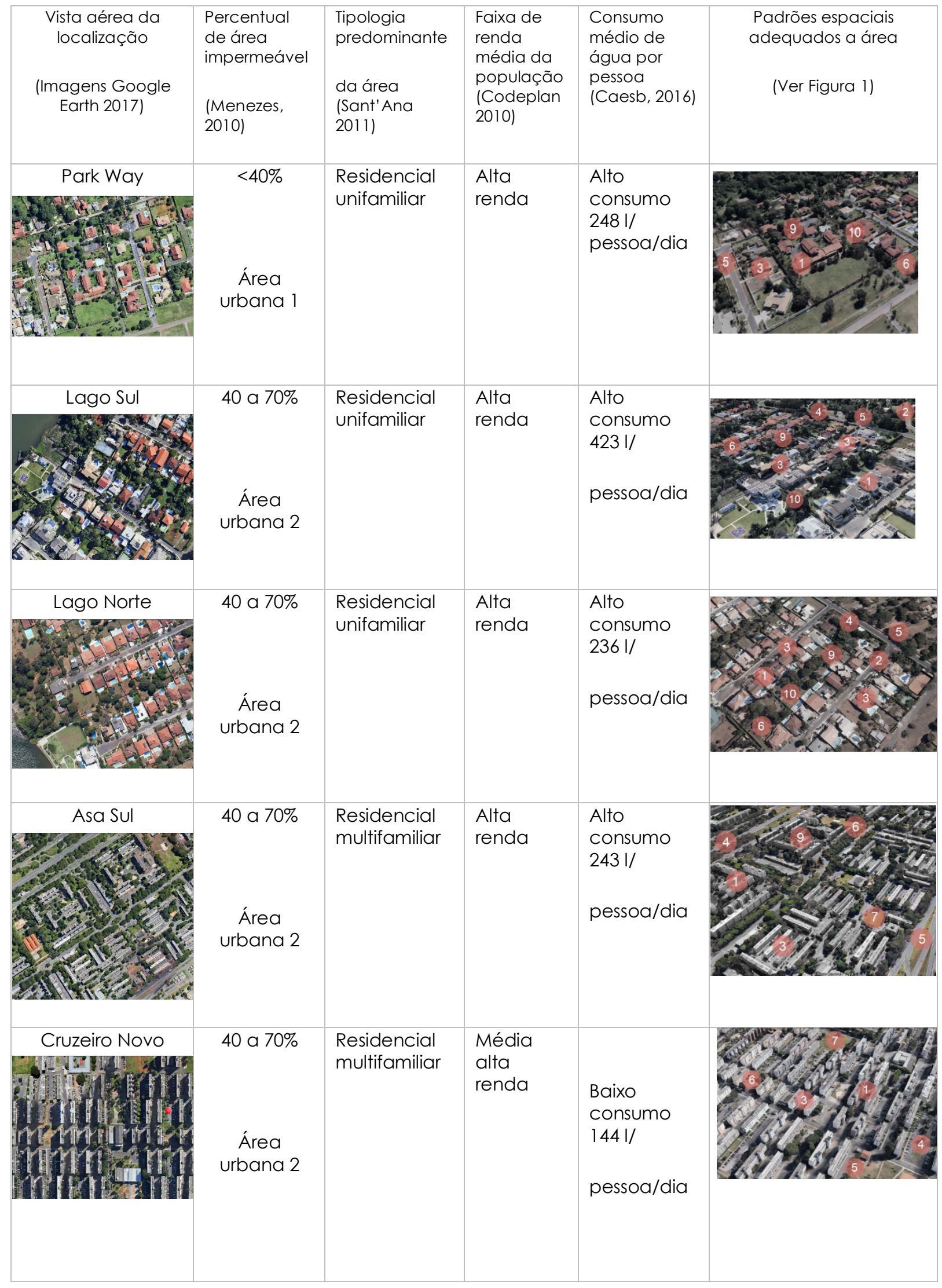




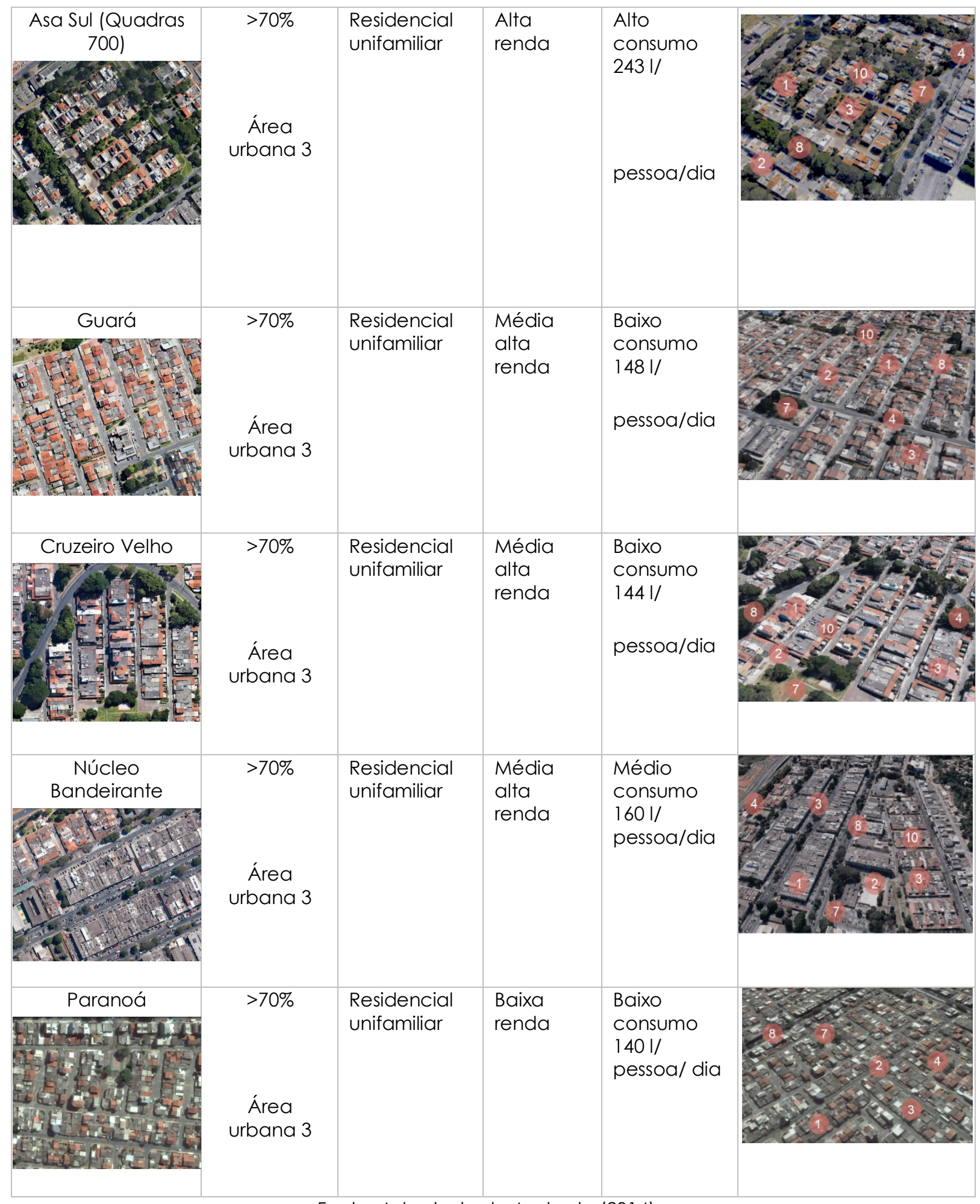

Fonte: Adaptado de Andrade (2014)

\section{CONCLUSÕES}

A heterogeneidade espacial é expressa em gradientes ou mosaicos, essenciais à explicação das interações e mudanças na cidade. O papel dos seres humanos, em múltiplas escalas de organização social (famílias, bairros, instituições) está ligado às escalas biofísicas dos sistemas urbanos. Esta pesquisa procurou demonstrar que por meio do diagnóstico da morfologia urbana é possível relacionar a heterogeneidade espacial dos padrões urbanos com 0 percurso da água da bacia hidrográfica do Lago Paranoá. Foi possível analisar que quanto 
maior a área de lote, onde predominantemente habita a população de renda mais alta, menor a densidade urbana, menor o escoamento superficial e maior o consumo e desperdício de água.

Com a crise hídrica, o racionamento de água provocou efeitos surpreendentes nas classes de rendas mais alta como o Lago Sul e o Lago Norte, evidenciando que é necessário pensar em estratégias de redução de consumo de água em padrões espaciais de lotes grandes que têm taxas de permeabilidade maior. Reforça-se assim o protagonismo do arquiteto e urbanista na correlação do desenho urbano e o ciclo hidrológico tendo em vista a importância da aproximação do profissional à gestão dos recursos hídricos.

\section{REFERÊNCIAS}

ADASA. AGÊNCIA REGULADORA DE ÁGUAS, ENERGIA E SANEAMENTO DO DISTRITO FEDERAL. Plano Distrital de saneamento básico e de gestão integrada de resíduos sólidos. Relatório síntese prognóstico, programas, projetos e ações. Julho, 2017.

AESBE. Associação Brasileira de Empresas de Saneamento. Santa Maria está no melhor nível desde maio de 2016, diz Adasa. Mesmo com bons números e fim do racionamento,

especialistas alertam para uso consciente da água. Disponível em

http://www.aesbe.org.br/dia-mundial-da-agua-apos-crise-hidrica-no-df-descoberto-opera-com-100por-mais-de-40-dias/. Acesso em maio de 2019

ANDRADE, Liza M. S., Conexões dos padrões espaciais dos ecossistemas urbanos: Procedimentos metodológicos com enfoque transdisciplinar para o processo de desenho urbano sensível à água englobando os níveis da comunidade e da paisagem. Tese (Doutorado) - Universidade de Brasília, 2014.

ANDRADE, L. M. S.; RIBAS, O. T. Desenhando com água na Expansão do Paranoá - DF. In: Anais do 5o PLURIS. Brasília (2012) Programa Drenagem Urbana Sustentável. Manual para Apresentação de Propostas, Brasilia. 2006.

BRASIL. AGÊNCIA NACIONAL DE ÁGUAS. Conjuntura dos Recursos Hídricos Brasil 2017.

Brasília, 2017. Disponível em http://www.snirh.gov.br/portal/snirh/centrais-deconteudos/conjuntura-dos-recursos-hidricos/conj2017_rel-1.pdf. Acesso em julho de 2019.

CAESB. Companhia de Saneamento Ambiental do Distrito Federal. 2016. Escassez hídrica e tarifa de contingência. Dados de consumo de água do DF 2016. Disponibilizados pela companhia, Julho 2016.

CODEPLAN COMPANHIA DE PLANEJAMENTO DO DISTRITO FEDERAL. Distribuição de Renda na Área Metropolitana Integrada de Brasília - AMIB. Disponível em:

<https://www.bnb.gov.br/documents/88765/89729/6distribuicao_renda_area_metropolitana _integrada_brasilia_amib.pdf/ca27581 f-81 1d-463e-8fdc-ed4d54dfed5e> Data de acesso: $10 / 07 / 2017$

HOLANDA, Frederico e KOHLSDORF, Gunter. A arquitetura como situação relacional. Grupo de pesquisa dimensões morfológicas no processo de urbanização - PPG- FAU/UnB, Brasília. 1994.

MENEZES, P. H. B. J. Avaliação do efeito das ações antrópicas no processo de escoamento superficial e assoreamento na Bacia do Lago Paranoá. Dissertação (Mestrado). Universidade de Brasilia, 2010. 
Rodrigues, Luísa. Ciclo da água urbano: análise da relação da heterogeneidade espacial e os fluxos de água da Bacia Hidrográfica do Lago Paranoá. Projeto de Iniciação Científica, $\mathrm{PIBIC/PROIC/Edital}$

SANT'ANA, D.R. A social-technical study of water consumption and water conservation in Brazilian dwellings. Tese (Doutorado). Oxford Brookes University, 2011.

SEGETH. GEOPORTAL. Mapas do DF. Disponível

em:<https://www.geoportal.segeth.df.gov.br/mapa/\#>. Data de acesso: 20/07/2017

SEINFRA-DF, SECRETARIA DE INFRA-ESTRUTURA E OBRAS, Plano de gerenciamento integrado de recursos hídricos do Distrito Federal. Brasília, 2011.

TUCCI, C. E. M.; MENDES, C. A. Avaliação Ambiental Integrada de Bacia Hidrográfica.Brasilia: MMA, 2008.

WSUD. WATER SENSITIVE URBAN DESIGN. CITY OF MELBOURNE GUIDELINES. Applying the Model WSUD Guidelines. Inner Melbourne Action Plan. Melbourne, 2008. 